\title{
Highly Efficient Cobalt (II) Catalyzed O-Acylation of Alcohols and Phenols under Solvent-Free Conditions
}

\author{
Shafeek A. R. Mulla*, Suleman M. Inamdar, Mohsinkhan Y. Pathan, Santosh S. Chavan \\ Chemical Engineering and Process Development Division, National Chemical Laboratory, Pune, India \\ Email: *sa.mulla@ncl.res.in
}

Received August 6, 2012; revised September 12, 2012; accepted September 28, 2012

\begin{abstract}
Solvent free, highly efficient method has been developed using ecofriendly, heterogeneous reusable cobalt chloride catalyst at ambient reaction conditions for the O-acylation of various alcohols and phenols with acetyl chloride in excellent yield in a short reaction time. The catalyst is recycled several times without loss of catalytic activity.
\end{abstract}

Keywords: Acetylation, Alcohol, Phenol, Acetyl Chloride, Cobalt (II) Chloride

\section{Introduction}

An esterification is a key and fundamental step to protect hydroxyl group during functional transformation in various organic synthesis [1-3]. However, protection and deprotection of hydroxyl functional group of alcohols and phenols being not only prime importance in pharmaceutical industries but also in the polymers, cosmetics, perfumes, plasticizers to achieve excellent yield to potential targeted synthetic compounds. Owing the importance of protection of hydroxyl functional group during the multisteps organic synthesis, the various methods for the protection of hydroxyl group of alcohols and phenols using varieties of reagent and catalysts such as $\mathrm{HgCl}_{2}$ [4], Montmorillonite [5], TMS-Cl [6], $\mathrm{TaCl}_{5}-\mathrm{SiO}_{2}$ [7], $\mathrm{ZnCl}_{2}$ [8], $\mathrm{ZnO}$ [9-10], Ru-catalyst [11], $\mathrm{Mg}\left(\mathrm{ClO}_{4}\right)$ [12], $\mathrm{SmI}_{2}$ [13], $\mathrm{CeCl}_{3}$ [14], perchlorates [15], $\mathrm{P}_{2} \mathrm{O}_{5} / \mathrm{Al}_{2} \mathrm{O}_{3}$ [16], $\mathrm{CoCl}_{2}$ [17-18], $\mathrm{ZrCl}_{4}$ [19], $\mathrm{NH}_{2} \mathrm{SO}_{3} \mathrm{H}$ [20], solid supported $\mathrm{HBF}_{4}-\mathrm{SiO}_{2}$ [21], lipase enzyme [22], $\mathrm{Al}(\mathrm{OTf})_{3}$ [23], $\mathrm{In}(\mathrm{OTf})_{3}$ [24], $\mathrm{Bi}(\mathrm{OTf})_{3}$ [25], polymer supported $\mathrm{Gd}(\mathrm{OTf})_{3}$ [26], Ce(OTf $)_{3}$ [27], Ag(OTf $)_{3}$ [28], molecular Iodine [29], nitro benzeneboronic acid [30], $\mathrm{NiCl}_{2}$ [31], $\mathrm{La}\left(\mathrm{NO}_{3}\right) \cdot 6 \mathrm{H}_{2} \mathrm{O}$ [32], DCC [33], Co(II)salen-complex [34], Melamine trisulfonic acid (MTSA) [35], ionic liquid [36-39], $\mathrm{ZnAl}_{2} \mathrm{O}_{4}$ [40], have been reported, however, the most common acetylating reagents used are acetyl chloride, acetic acid, acetic anhydride or any other protic acid [41].

However, all the above methods are badly suffer from one/or other limitations and drawbacks such as drastic reaction conditions, long reaction time, high temperature, use of moisture sensitive, toxic, expensive reagents and catalysts. In addition these limitations, the catalysts are

\footnotetext{
"Corresponding author.
}

non-recoverable besides the formation of toxic side product and poor yield for the desired product in presence of organic solvent.

Therefore, considering all the above facts, still there is a need and demand to develop a solvent free, greener and an economical protocol and catalysts for protection of hydroxyl of alcohols and phenols by esterification. Therefore, herein we wish to report a solvent-free, a cheap, mild, rapid and efficient protocol for the O-acylation of alcohols and phenols with acetyl chloride over cobalt (II) chloride catalyst at room temperature (Schemes 1).

$$
\mathrm{R}-\mathrm{OH} \underset{\begin{array}{c}
\text { AcCl (1.2 equiv) } \\
\text { room temp } \\
-\mathrm{HCl}
\end{array}}{\stackrel{1 \mathrm{~mol}^{\mathrm{CoCl}} \mathrm{CoC}_{2}}{\longrightarrow}} \mathrm{R}-\mathrm{OAC}
$$

R= Ph, Allyl, Benzyl, Naphthyl, Aliphatic, etc.

Scheme 1. Cobalt (II) chloride catalyzed O-acylation of alcohols and phenols.

\section{Experimental Section}

All chemicals and reagents were procured from suppliers and used without further purification. The products were analyzed by a 5765 NUCON Gas Chromatograph with FID detector using stainless steel column $4 \mathrm{~m}$ length $\mathrm{x}$ 1/8 inch O.D. $x 2 \mathrm{~mm}$ I.D., packed with $10 \%$ SE-30 on Chromosorb-W with mesh size 80-100 and also characterized using ${ }^{1} \mathrm{H}$ NMR, ${ }^{13} \mathrm{C}$ NMR spectra. The NMR spectrums of product were obtained using Bruker AC$200 \mathrm{MHz}$ spectrometer with TMS as the internal stan- 
dard.

\subsection{General Experimental Procedure for O-Acetylation of Alcohols and Phenols}

The alcohol or phenol $(5 \mathrm{mmol})$ in acetyl chloride (6 mmol) was taken in $50 \mathrm{ml}$ round bottom flask. To this reaction mixture $1 \mathrm{~mol} \%$ cobalt (II) chloride catalyst was added and then mixture was stirred at room temperature under solvent free conditions. The influence of acylating agents was investigated using phenol, 4-methyl phenol and chloroethanol as substrate. The completion of the reactions was monitored by GC. After the completion of reaction, the mixture was diluted with ethyl acetate (25 $\mathrm{ml}$ ) and the catalyst was recovered by filtration. The filtrate was washed with $\mathrm{NaHCO}_{3}$ and then with water, dried over anhydrous $\mathrm{Na}_{2} \mathrm{SO}_{4}$. The dry filtrate was concentrated under vacuum to obtain the pure product.

\section{Results and Discussion}

Acylation of phenol (5 mmol) was studied with acetyl chloride (6 mmol) in presence of $1 \mathrm{~mol} \%$ cobalt (II) chloride catalyst under solvent free condition at room temperature to afford phenyl acetate in $99 \%$ yield in 20 seconds. However, the acetylation reaction of phenol was inefficient in absence of cobalt (II) chloride. After the successful acetylation of phenol with excellent yield to phenyl ester, the influence of acylating agents was invest tigated using phenol, 4-methyl phenol and chloroethanol as substrate and results are summarized in Table $\mathbf{1}$. The influence of the acylating agent's study (entries 1 - 3, Table 1) reveals that reactivity of acetyl chloride is ex tremely higher than that of acetic anhydride and acetic acid over the cobalt (II) chloride catalyst under solvent free conditions at room temperature.

The results on influence of acylating agents promoted us to evaluate the scope of this methodology for different types of primary, secondary, benzylic, allylic, cyclic alcohols and phenols using acetyl chloride as acylating agent (Scheme 1).

A number of substituted phenols and alcohols such as 4-tert-butyl phenol, 2- tert-butyl, 4-methyl phenol, pcresol, o-cresol, m-cresol, 2-hydroxy benzaldehyde, 1naphthol and 2-naphthol (entries 2 - 9, Table 2) and butanol; hexanol; heptanol; 1, 8-octandiol; chloro ethanol; Lauryl alcohol and 2-butanol (entries 1 - 7, Table 3), secondary alcohols (entries 8 - 9, Table 3 ), allylic alcohol (entry 10, Table 3) and benzylic alcohols (entry 11 12, Table 3) were acetylated respectively, in good to excellent yield without any difficulties.

The results (Tables 2 and 3 ) on the acetylation of alco hols and phenols reveal that the good to excellent yield up to $99 \%$ was achieved in very short reaction time
Table 1. Influence of acylating agents on various substrate ${ }^{\mathrm{a}}$.

\begin{tabular}{|c|c|c|c|c|c|c|}
\hline \multirow{2}{*}{ Entry } & \multirow{2}{*}{ Substrate } & \multirow{2}{*}{ Product } & \multirow{2}{*}{$\begin{array}{l}\text { Time } \\
\text { (s) }\end{array}$} & \multicolumn{3}{|c|}{ (\%) Yield ${ }^{\mathrm{b}}$} \\
\hline & & & & $\mathrm{AcCl}$ & $\mathrm{Ac}_{2} \mathrm{O}$ & $\mathrm{AcOH}$ \\
\hline 1 & & & $\begin{array}{c}20 \\
3600\end{array}$ & $\begin{array}{l}99 \\
-\end{array}$ & $\begin{array}{l}\text { NR } \\
\text { NR }\end{array}$ & $\begin{array}{l}\text { NR } \\
\text { NR }\end{array}$ \\
\hline 2 & & & $\begin{array}{c}15 \\
3600\end{array}$ & $\begin{array}{c}99 \\
-\end{array}$ & $\begin{array}{l}35 \\
39\end{array}$ & $\begin{array}{l}\text { NR } \\
\text { NR }\end{array}$ \\
\hline 3 & $\mathrm{Cl} \bigcirc \mathrm{OH}$ & $\leadsto \mathrm{OAC}$ & $\begin{array}{c}10 \\
3600\end{array}$ & $\begin{array}{c}99 \\
-\end{array}$ & $\begin{array}{l}67 \\
99\end{array}$ & $\begin{array}{l}\text { NR } \\
12\end{array}$ \\
\hline
\end{tabular}

${ }^{a}$ Reaction conditions: The substrate (5 mmol), acetylating agent (6 mmol), 1 $\mathrm{mol} \% \mathrm{CoCl}_{2}$, room temperature; ${ }^{\mathrm{b}} \mathrm{GC}$ yield. NR: No Reaction.

Table 2. Cobalt (II) chloride catalyzed acetylation of phenols with acetyl chloridea.

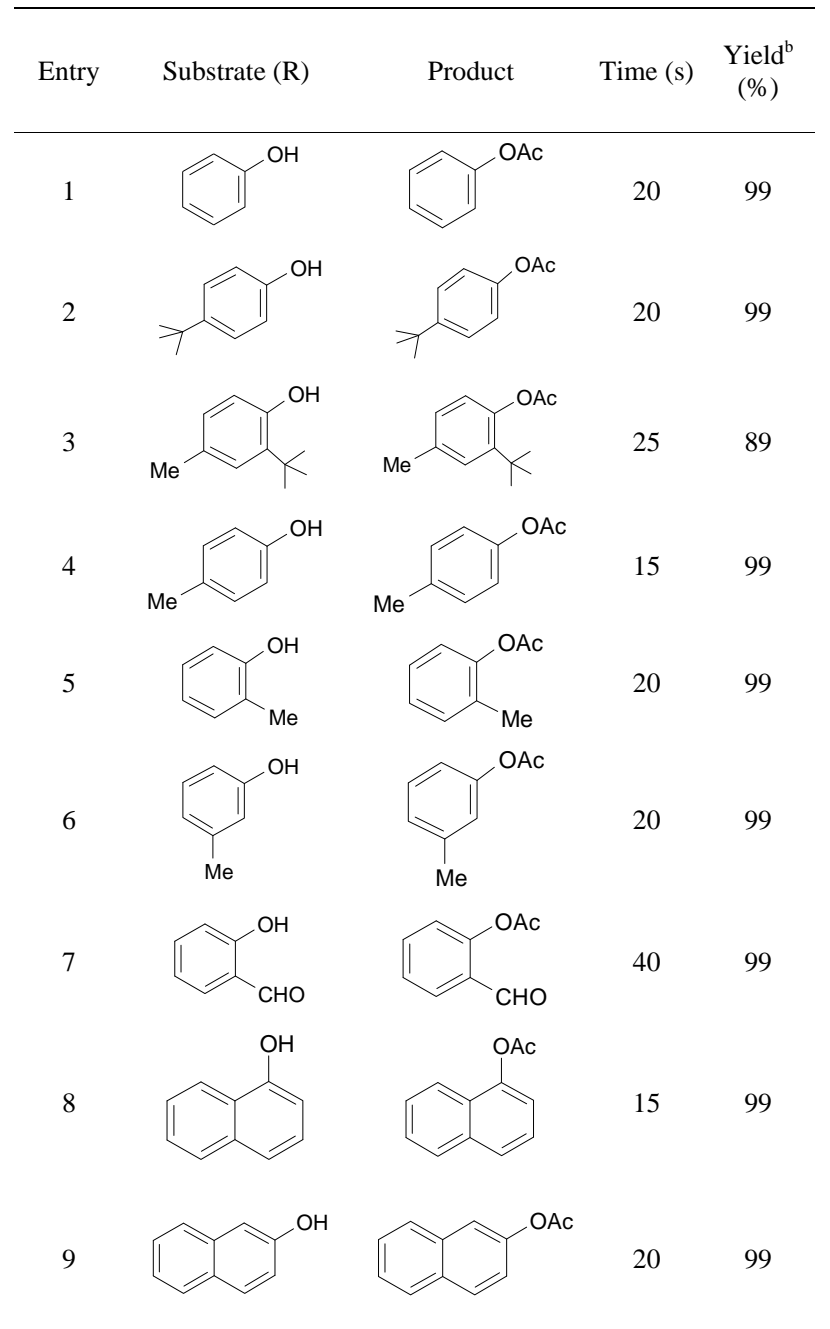

${ }^{\mathrm{a}}$ Reaction conditions: The substrate $(5 \mathrm{mmol}), \mathrm{CH}_{3} \mathrm{COCl}(6 \mathrm{mmol} / \mathrm{OH}$ group), $1 \mathrm{~mol} \% \mathrm{CoCl}_{2}$, room temperature; ${ }^{\mathrm{b}} \mathrm{GC}$ yield; ' without $\mathrm{CoCl}_{2}$ catalyst. 
Table 3. Cobalt (II) chloride catalyzed acetylation of alcohols with acetyl chloride ${ }^{a}$.

\begin{tabular}{|c|c|c|c|c|}
\hline Entry & Substrate (R) & Product & $\begin{array}{l}\text { Time } \\
\text { (s) }\end{array}$ & $\begin{array}{c}\text { Yield }^{b} \\
(\%)\end{array}$ \\
\hline 1 & $\mathrm{OH}$ & OAC & 10 & 95 \\
\hline 2 & $\mathrm{OH}$ & OAC & 10 & 99 \\
\hline 3 & & $\mathrm{OAC}$ & 15 & 98 \\
\hline 4 & Hо & OAC & 15 & 99 \\
\hline 5 & $\mathrm{Cl}$ & $\mathrm{Cl}^{-}$ & 10 & 99 \\
\hline 6 & $\widehat{\mathrm{OH}}$ & $\widehat{O A C}$ & 15 & 99 \\
\hline 7 & & $\mathrm{Me}$ & 10 & 98 \\
\hline 8 & & & 10 & 99 \\
\hline 9 & $\mathrm{HO}$ & OAC & 35 & 92 \\
\hline 10 & $\mathrm{H}$ & & 10 & 82 \\
\hline 11 & 아 & OAc & 50 & 75 \\
\hline 12 & & & 35 & 98 \\
\hline
\end{tabular}

${ }^{a}$ Reaction conditions: The substrate $(5 \mathrm{mmol}), \mathrm{CH}_{3} \mathrm{COCl}$ (6 mmol/OH group), $1 \mathrm{~mol} \% \mathrm{CoCl}_{2}$, room temperature; ${ }^{\mathrm{b}} \mathrm{GC}$ yield.

(10 - 50 seconds). Further, the result indicates that the cobalt (II) chloride catalyst shows remarkably high catalytic activity and efficiency not only with primary alcohols and phenols but also with sterically hindered secondary, benzylic, allylic, cyclic alcohols and phenols under mild and solvent free reaction conditions at room temperature. The catalytic activity and/ or recyclability study of $1 \mathrm{~mol} \%$ cobalt (II) chloride catalyst was performed for the acetylation of phenol (Scheme 2, Table 4).

The catalyst was recovered quantitatively four times by simple filtration of the reaction mixture and subsequently washed with ethyl acetate and water. The recovered cobalt (II) chloride catalyst was reused four times (Run 2-5, Table 4) for the acetylation of phenol with acetyl chloride to give the phenyl acetate in $98 \%$ - 99\% yield, which is almost comparable with fresh catalyst (Run 1, Table 4). This result clearly shows that the recycled cobalt (II) chloride gives excellent yield without loss of catalytic activity.

As shown in the Scheme 3, the plausible reaction mechanism and/ or catalytic cycle for the acetylation of alcohols and phenols using acetyl chloride as acylating agents over the cobalt (II) chloride under the solvent free

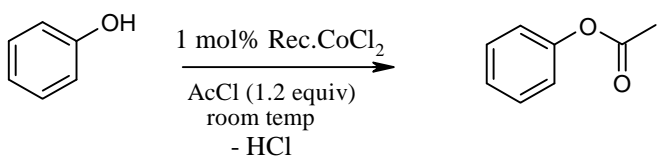

Scheme 2. Recyclability study of cobalt (II) chloride catalyst for acetylation of phenols with acetyl chloride.

Table 4. Recyclability study of cobalt (II) chloride for acetylation of phenol with acetyl chloride ${ }^{a}$.

\begin{tabular}{ccc}
\hline No. of Run & Time (s) & Yield (\%) \\
\hline Run 1 (Fresh catalyst) & 20 & 99 \\
Run 2 & 20 & 99 \\
Run 3 & 25 & 98 \\
Run 4 & 25 & 99 \\
Run 5 & 30 & 99 \\
\hline
\end{tabular}

${ }^{\mathrm{a}}$ Reaction conditions: phenol (5 mmol) $\mathrm{CH}_{3} \mathrm{COCl}(6 \mathrm{mmol}) 1 \mathrm{~mol} \%$ of $\mathrm{CoCl}_{2}$ at room temperature Catalyst recovery $=97 \% \pm 2 \%$; ${ }^{b} \mathrm{GC}$ yield.

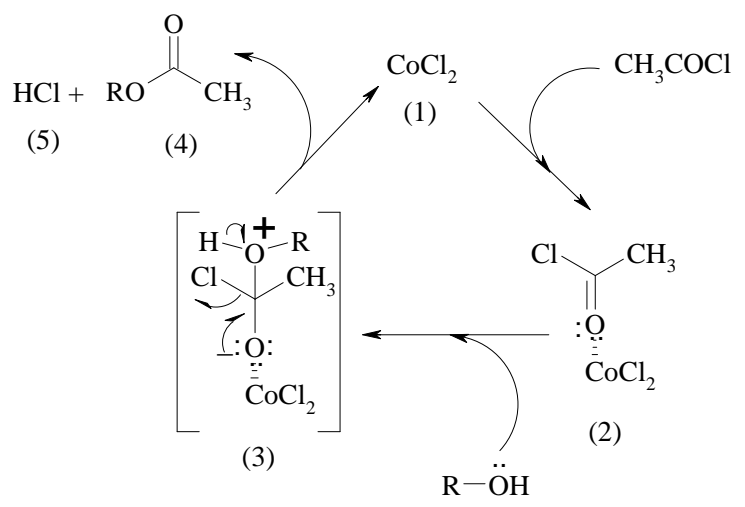

R= Ph, Allyl, Benzyl, Naphthyl, Aliphatic, etc.

Scheme 3. The proposed catalytic cycle for the acetylation reaction over $\mathrm{CoCl}_{2}$ catalyst.

condition at room temperature is not clear so far, however, the results obtained in the present study shed some light on these aspects.

The carbonyl group of acetyl chloride is known to coordinating on Lewis acid sites of the $\mathrm{CoCl}_{2}$ catalyst surface via intermediate (2) to activate itself being reactive electrophile. The activation of carbonyl group of acetyl chloride encourage the attack by the oxygen of alcohols and/or phenols as an nucleophile and subsequently stabilization intermediate (3) and release of leaving group followed by formation of the corresponding acetate (4) by the loss of hydrochloric acid (5).

\section{Conclusions}

In conclusion, cobalt (II) chloride is an efficient, versatile, ecofriendly, inexpensive, nontoxic, reusable heterogeneous and green catalyst for the acetylation of alcohols and phenols using acetyl chloride as acetylating reagent. The following features make this methodology attractive: 1) 
its simplicity, clean, efficient, rapid and mild reactions conditions; 2) the protocol is very general and it works well with variety of alcohols and phenols affording good to excellent yields; 3) the reaction carried out at room temperature in absence of the organic solvent; 4) the relative reactivity of acylating agents over the cobalt (II) chloride catalyst were found to be higher in the order: acetyl chloride $>$ acetic anhydride $>$ acetic acid; 5) the recovered and reused catalyst without further purifica tions gave $98 \%$ - 99\% yield without loss of catalytic activeity.

\section{Acknowledgements}

SMI, MYP and SSC thanks to CSIR New Delhi for a SRF and JRF, respectively. The authors also thank to Dr. V. V. Ranade, Chair, CE-PD for their encouragement and support.

\section{REFERENCES}

[1] S. S. Rana, J. J. Barlow and K. L. Matta, "The Selective Acetylation of Primary Alcohols in the Presence of Secondary Alcohols in Carbohydrates” Tetrahedron Leters, Vol. 22, No. 50, 1981, pp. 5007-5010; doi:10.1016/S0040-4039(01)92405-0

[2] T. S. Li, Y. L. Li and X. T. Liang, "Studies of the Synthesis of Biomarkers. VII. Synthesis of 5 Alpha-(17R,20R)14,15-Secocholestane,” Steroids, Vol. 55, No. 6, 1990, pp. 263-265.

[3] P. J. Kocienski, "Protecting Groups," Theime, Stuttgard, 1994.

[4] R. Ghosh, M. Swarupnanda and A. Chakraborty, "Mercury Chloride Assisted Cyclisation towards Benzimidazoles by Focused Microwave Irradiation,” Tetrahedron Leters, Vol. 46, No. 1, 2005, pp. 177-180.

[5] A-I. Li, T.-S. Li and T.-H. Ding, "Montmorillonite K-10 and KSF as Remarkable Acetylation Catalysts," Chemical Communications, No. 15, 1997, pp. 1389-1390. doi:10.1039/a703389c

[6] R. Kumareswaran, A. Gupta and Y. D. Vankar, "Chlorotrimethylsilane Catalysed Acetylation of Alcohols" Synthetic Communications, Vol. 27, No. 2, 1997, pp. 277-282. doi:10.1080/00397919708005028

[7] S. Chandrashekhar, T. Ramchandar and T. Mohamed, "Acylation of Alcohols with Acetic Anhydride Catalyzed by $\mathrm{TaCI}_{5}$ : Some Implications in Kinetic Resolution” Tetrahedron Letters, Vol. 39, No. 20, 1998, pp. 3263-3266. doi:10.1016/S0040-4039(98)00465-1

[8] P. Yadav, R. Lagarkha and A. Zahoor, "Comparative Study of Acetylation of Alcohols and Phenols with Different Acetylating Agents Using Zinc Chloride as Catalyst under Solvent Free Conditions at Room Temperature,” Asian Journal of Chemistry, Vol. 22, 2010, pp. 5155-5158.

[9] M. H. Sarvari and H. Sharghi, "Zinc Oxide $(\mathrm{ZnO})$ as a New, Highly Efficient, and Reusable Catalyst for Acylation of Alcohols, Phenols and Amines under Solvent Free
Conditions,” Tetrahedron, Vol. 61, No. 46, 2005, pp. 10903-10907. doi:10.1016/j.tet.2005.09.002

[10] F. Tamaddon, M. A. Amrollahi and L. Sharafat, "A Green Protocol for Chemoselective O-Acylation in the Presence of Zinc Oxide as Heterogeneous, Reusable and Eco-Friendly Catalyst," Tetrahedron Leters, Vol. 46, No. 45, 2005, pp. 7841-7844. doi:10.1016/j.tetlet.2005.09.005

[11] K. D. Surya, "Ruthenium (III) Chloride Catalysed Acylation of Alcohols, Phenols, Thiols and Amines," Tetrahedron Leters, Vol. 45, No. 14, 2004, pp. 2919-2922. doi:10.1016/j.tetlet.2004.02.071

[12] G. Bartoli, M. Bosco, R. Dalpozzo, E. Marcantoni, M. Massaccesi, S. Rinaldi and L. Sambri, " $\mathrm{Mg}\left(\mathrm{ClO}_{4}\right)_{2}$ as a Powerful Catalyst for the Acylation of Alcohols under Solvent-Free Conditions,” Synlett, No. 1, 2003, pp. 39-42.

[13] Y. Ishii, M. Takeno, Y. Kawasaki, A. Muromachi, Y. Nishiyama and S. Sakaguchi, "Acylation of Alcohols and Amines with Vinyl Acetates Catalyzed by $\mathrm{Cp}_{2}{ }_{2} \mathrm{Sm}(\mathrm{OTf})_{2}$," Journal of Organic Chemistry, Vol. 61, No. 9, 1996, pp. 3088-3092. doi:10.1021/jo952168m

[14] E. Torregiani, S. Gianfranco, A. Minassi and G. Appendino, "Cerium (III) Chloride-Promoted Chemoselective Esterification of Phenolic Alcohols,” Tetrahedron Letters, Vol. 46, No. 13, 2005, pp. 2193-2196. doi:10.1016/j.tetlet.2005.02.042

[15] B. P. Bandgar, V. T. Kamble, V. S. Sadavarte and V. S. Uppalla, "Selective Sulfonylation of Arenes and Benzoylation of Alcohols Using Lithium Perchlorate as a Catalyst Under Neutral Conditions,” Synlett, No. 5, 2002, pp. 735738. doi:10.1055/s-2002-25345

[16] A. Zarei, A. R. Hajipour and L. Khazdooz, " $\mathrm{P}_{2} \mathrm{O}_{5} / \mathrm{Al}_{2} \mathrm{O}_{3}$ as an Efficient Heterogeneous Catalyst for the Acetylation of Alcohols, Phenols, Thiols, and Amines under Solvent-Free Conditions,” Synthetic Communications, Vol. 41, No. 12, 2011, pp. 1772-1785. doi:10.1080/00397911.2010.492197

[17] S. Velusamy, S. Borpuzari and T. Punniyamurthy, "Cobalt(II)-Catalyzed Direct Acetylation of Alcohols with Acetic Acid,” Tetrahedron, Vol. 61, No. 8, 2005, pp. 2011-2015. doi:10.1016/j.tet.2005.01.006

[18] J. Iqbal and R. R. Srivastva, "Cobalt (II) Chloride Catalyzed Acylation of Alcohols with Acetic Anhydride: Scope and Mechanism,” Journal of Organic Chemistry, Vol. 57, No. 7, 1992, pp. 2001-2007. doi:10.1021/jo00033a020

[19] A. K. Chakraborty and R. Gulhane, "Zirconium(IV) Chloride as a New, Highly Efficient, and Reusable Catalyst for Acetylation of Phenols, Thiols, Amines, and Alcohols under Solvent-Free Conditions,” Synlett, No. 4, 2004, pp. 627-630. doi:10.1055/s-2004-815442

[20] T.-S. Jin, Y.-R. Ma, Z.-H. Zhang and T.-S. Li, "Salfamic Acid Catalysed Acetylation of Alcohols and Phenols with Acetic Anhydride,” Synthetic Communications, Vol. 28, No. 17, 1998, pp. 3173-3177. doi:10.1080/00397919808004417

[21] A. K. Chakraborty and R. Gulhane, "Fluoroboric Acid Adsorbed on Silica Gel as a New and Efficient Catalyst for Acylation of Phenols, Thiols, Alcohols, and Amines," Tetrahedron Letters, Vol. 44, No. 17, 2003, pp. 35213525. doi:10.1016/S0040-4039(03)00683-X 
[22] B. Berger, D. G. Rabiller, K. Konigsberger, K. Faber and H. Griengl, "Enzymatic Acylation Using Acetic Anhydrides: Crucial Removal of Acid,” Tetrahedron: Asymmetry, Vol. 1, No. 8, 1990, pp. 541-546. doi:10.1016/S0957-4166(00)80545-5

[23] K. Ahmed, A. K. Naseer, R. Srinivasan, Y. V. Srikanth and T. Krishnaji, "Al(OTf $)_{3}$ as a Highly Efficient Catalyst for the Rapid Acetylation of Alcohols, Phenols and Thiophenols under Solvent-Free Conditions," Tetrahedron Letters, Vol. 48, No. 22, 2007, pp. 3813-3818. doi:10.1016/j.tetlet.2007.03.162

[24] K. C. Kamlesh, G. F. Christopher, L. Ian and W. David, "Indium Triflate: An Efficient Catalyst for Acylation Reactions,” Synlett, No. 11, 1999, pp. 1743-1744.

[25] O. Akihiro, T Chiaki, K. Atsushi and O. Junzo, "Highly Powerful and Practical Acylation of Alcohols with Acid Anhydride Catalyzed by $\mathrm{Bi}(\mathrm{OTf})_{3}$," Journal of Organic Chemistry, Vol. 66, No. 26, 2001, pp. 8926-8934. doi:10.1021/jo0107453

[26] H.-J. Yoon, S.-M. Lee, J.-H. Kim, H.-J. Cho, J.-W. Choi, S.-H. Lee and Y.-S. Lee, "Polymer-Supported Gadolinium Triflate as a Convenient and Efficient Lewis Acid Catalyst for Acetylation of Alcohols and Phenols," Tetrahedron Letters, Vol. 49, No. 19, 2008, pp. 3165-3171. doi:10.1016/j.tetlet.2008.03.005

[27] R. Dalpozzo, A. D. Nino, L. Maiuolo, A. Proeopio, M. Nardi, G. Bartoli and R. Romeo, "Highly Efficient and Versatile Acetylation of Alcohols Catalyzed by Cerium (III) Triflate,” Tetrahedron Letters, Vol. 44, No. 30, 2003, pp. 5621-5624. doi:10.1016/S0040-4039(03)01358-3

[28] R. Das and D. Chakraborty, "Silver Triflate Catalyzed Acetylation of Alcohols, Thiols, Phenols, and Amines," Synthesis, Vol. 2011, No. 10, 2011, pp. 1621-1625.

[29] J. W. Bosco, A. Aditya and A. K. Saikia, "Molecular Iodine Catalyzed Selective Acetylation of Alcohols with Vinyl Acetate,” Tetrahedron Letters, Vol. 47, No. 24, 2006, pp. 4065-4068.

[30] R. H. Tale and R. N. Adude, "A Novel 3-Nitrobenzeneboronic Acid as an Extremely Mild and Environmentally Benign Catalyst for the Acetylation of Alcohols under Solvent-Free Conditions," Tetrahedron Letters, Vol. 47, No. 40, 2006, pp. 7263-7265. doi:10.1016/j.tetlet.2006.07.046

[31] G. Meshram, G and V. D. Patil, "Simple and Efficient Method for Acetylation of Alcohols, Phenols, Amines, and Thiols Using Anhydrous $\mathrm{NiCl}_{2}$ under Solvent-Free Conditions," Synthetic Communications, Vol. 39, No. 14, 2009, pp. 4384-4395. doi:10.1080/00397910902906529

[32] T. S. Reddy, M. Narasimhulu, N. Suryakiran, K. C.
Mahesh, K. Ashalatha and Y. Venkateswarlu, “A Mild and Efficient Acetylation of Alcohols, Phenols and Amines with Acetic Anhydride Using $\mathrm{La}\left(\mathrm{NO}_{3}\right)_{3} \cdot 6 \mathrm{H}_{2} \mathrm{O}$ as a Catalyst under Solvent-Free Conditions," Tetrahedron Letters, Vol. 47, No. 38, 2006, pp. 6825-6829. doi:10.1016/j.tetlet.2006.07.059

[33] A. Hassner and V. Alexanian, "Direct Room Tempareture Esterification of Carboxylic Acids," Tetrahedron Letters, Vol. 19, No. 46, 1978, pp. 4475-4478. doi:10.1016/S0040-4039(01)95256-6

[34] R. Fatemeh, “A Heterogeneous Cobalt(II) Salen Complex as an Efficient and Reusable Catalyst for Acetylation of Alcohols and Phenols," Tetrahedron Letters, Vol. 50, No. 4, 2009, pp. 395-397. doi:10.1016/j.tetlet.2008.11.024

[35] S. Farhad, A. Z. Mohammad and A. Ali-Reza, "Efficient Acetylation of Alcohols, Phenols, and Amines Catalyzed by Melamine Trisulfonic Acid,” Synthetic Communications, Vol. 40, No. 7, 2010, pp. 1022-1028. doi:10.1080/00397910903029941

[36] W. Dong-Sheng, L. Gui-Yun and P. Yan-Qing, "Chloroferrate(III) Ionic Liquid as Recyclable Catalyst for the Acetylation of Alcohols and Phenols and for 1,1-Diacylation of Aldehydes," Journal of the Chinese Chemical Society, Vol. 56, 2009, pp. 834-838.

[37] I. Lopez, J. L. Bravo, M. Caraballo, J. L. Barneto and G. Silvero, "Task-Oriented Use of Ionic Liquids: Efficient Acetylation of Alcohols and Phenols," Tetrahedron Letters, Vol. 52, No. 26, 2011, pp. 3339-3341. doi:10.1016/j.tetlet.2011.04.079

[38] S. G. Lee and J. H. Park, "Metallic Lewis Acids Catalysed Acetylation of Alcohols with Acetic Anhydride and Acetic Acid in Ionic Liquid: Study on Reactivity and Reusability of the Catalyst,” Journal of Molecular Catalysis A: Chemical, Vol. 194, No. 1-3, 2003, pp. 49-52. doi:10.1016/S1381-1169(02)00532-0

[39] A. R. Hajipour, L. Khazdooz and A. E. Ruoho, "Bronsted Acidic Ionic Liquid as an Efficient Catalyst for Acetylation of Alcohols and Phenols," Journal of the Chinese Chemical Society, Vol. 56, No. 2, 2009, pp. 398-403.

[40] S. Farhadi, S. Panahandehjoo, "Spinel-Type Zinc Aluminate $\left(\mathrm{ZnAl}_{2} \mathrm{O}_{4}\right)$ Nanoparticles Prepared by the Co-Precipitation Method: A Novel, Green and Recyclable Heterogeneous Catalyst for the Acetylation of Amines, Alcohols and Phenols under Solvent-Free Conditions," Applied Catalysis A: General, Vol. 382, No. 2, 2010, pp. 293-302. doi:10.1016/j.apcata.2010.05.005

[41] T. W. Green and P. G. Wuts, "Protective Groups in Organic Synthesis,” 2nd Edition, Wiley, New York, 1991. 